\title{
Real-World Data from the First U.S. Commercial Users of an Implantable Continuous Glucose Sensor
}

\author{
Patricia Sanchez, MS, Samanwoy Ghosh-Dastidar, PhD, \\ Katherine S. Tweden, PhD, and Francine R. Kaufman, MD
}

\begin{abstract}
Background: The Eversense ${ }^{\circledR}$ Continuous Glucose Monitoring (CGM) System, with the first 90-day implantable sensor, received FDA (Food and Drug Administration) approval in June 2018. No real-world experience has been published.

Methods: Deidentified sensor glucose (SG) data from August 1, 2018 to May 11, 2019 in the Eversense Data Management System (DMS) were analyzed for the first 205 patients who reached a 90-day wear period on the Eversense CGM system. The mean SG, standard deviation (SD), median interquartile range, coefficient of variation $(\mathrm{CV})$, glucose measurement index $(\mathrm{GMI})$, and percent and time in minutes across glucose ranges were computed for the 24-h time period, the nighttime (00:00-06:00), and by 30-day wear periods. Sensor accuracy, sensor reinsertion rate, transmitter wear time, and safety data were assessed.

Results: Of the 205 patients, 129 identified as type 1,18 as type 2, and 58 were unreported. Fifty were CGM naive, 112 had prior CGM experience, and 43 were unreported. The mean SG was $161.8 \mathrm{mg} / \mathrm{dL}$, SD was $57.4 \mathrm{mg} / \mathrm{dL}, \mathrm{CV}$ was 0.35 , and GMI was $7.18 \%$. Percent SG at $<54 \mathrm{mg} / \mathrm{dL}$ was $1.2 \%(18 \mathrm{~min}),<70 \mathrm{mg} / \mathrm{dL}$ was $4.1 \%(59.7 \mathrm{~min})$, time in range $(\geq 70-180 \mathrm{mg} / \mathrm{dL})$ was $62.3 \%(897.7 \mathrm{~min}),>180-250 \mathrm{mg} / \mathrm{dL}$ was $21.9 \%$ (315.8 $\mathrm{min})$, and $>250 \mathrm{mg} / \mathrm{dL}$ was $11.6 \%(166.7 \mathrm{~min})$. Nighttime values were similar. The glucometric values were similar over 30-day time periods of the sensor wear. The mean absolute relative difference (SD) using 27,708 calibration paired points against home blood glucose meters was $11.2 \%$ (11.3\%). The sensor reinsertion rate was $78.5 \%$. The median transmitter wear time was $83.6 \%$. There were no related serious adverse events. Conclusion: The Eversense real-world data showed promising glycemic results, sensor accuracy, and safety. These data suggest that the Eversense CGM system is a valuable tool for diabetes management.
\end{abstract}

Keywords: Continuous glucose monitoring, Implantable sensor, Type 1 diabetes, Type 2 diabetes, Glucometrics, Safety.

\section{Introduction}

$\mathbf{T}$ HE GOAL OF intensive diabetes management is to obtain optimal glycemic control to prevent and reduce diabetes complications. The risk of increasing hypoglycemia, however, has made disease management difficult for many patients. ${ }^{1}$ Continuous glucose monitoring (CGM) has been demonstrated to help improve glycemic control while reducing hypoglycemia when compared to regular capillary self-measurement of blood glucose (SMBG). ${ }^{2,3}$ Randomized controlled trials have documented reduction of hemoglobin
A1c (HbA1c), the area under the hypoglycemia curve, episodes of hypoglycemia, and time spent in hypoglycemia, as well as increased confidence concerning detection of hypoglycemia with CGM compared to $\mathrm{SMBG}^{2-7}$ In addition, these studies have shown that wearing CGM devices the majority of the time $(>80 \%)$ is required to achieve these beneficial outcomes. ${ }^{4,7}$ While randomized controlled studies have been important to establish the role of CGM, real-world data derived from CGM data management systems are also important to establish glucometric outcomes of patients using CGM devices at home.

(C) Patricia Sanchez, et al., 2019; Published by Mary Ann Liebert, Inc. This Open Access article is distributed under the terms of the Creative Commons License (http://creativecommons.org/licenses/by/4.0), which permits unrestricted use, distribution, and reproduction in any medium, provided the original work is properly credited. 
The Eversense ${ }^{\circledR}$ CGM system (Senseonics, Inc., Germantown, MD) is the first long-term, 90-day duration implantable sensor, which was approved by the Food and Drug Administration (FDA) in June 2018 for use in patients with diabetes 18 years of age and older. Three accuracy and safety trials $^{8-10}$ were performed showing optimal mean absolute relative difference (mean ARD) between sensor glucose (SG) data and the reference laboratory glucose values (Yellow Springs Instrument [YSI]) of $8.5 \%$, optimal mean absolute difference (mean AD) performance in the hypoglycemia range $(<70 \mathrm{mg} / \mathrm{dL})$ of $7.2 \%-7.6 \%$, and hypoglycemia and hyperglycemia alert performance detection rates of $93 \%$ and $96 \%$, respectively. The percent of time SG values were between 70 and $180 \mathrm{mg} / \mathrm{dL}$ (time in range [TIR]) was between $57 \%$ and $59 \%$ (data on file; Senseonics, Inc.). The safety profile was promising during these trials, with few skin reactions reported to the silicone-based adhesive used to place the transmitter, infrequent skin infections, and only one related serious adverse event (SAE) of failure to remove a sensor on the first attempt, which was adjudicated related to the removal procedure. This event became a SAE due to the surgeon electing to use general anesthesia to remove the sensor.

The Eversense sensor is implanted using a brief officebased procedure performed by endocrinologists, nurse practitioners, and physician assistants. The Eversense system computes an interstitial glucose value using a fluorescencebased technology activated using radio frequency energy every $5 \mathrm{~min}$. When the removable transmitter is worn over the sensor on top of the skin, it transmits glucose values via Bluetooth Low Energy to the Eversense app on the patient's iOS or Android smartphone, which can be shared with up to five additional individuals. Alerts can be set at actual and predictive high and low SG thresholds and at rapid rates of glucose change. The transmitter has an on-body vibration that alerts patients when their actual and predictive glucose thresholds have been triggered in either the presence or absence of the smartphone. SG data and patient-entered inputs such as meals, exercise, and insulin are automatically uploaded into the Eversense Data Management System (DMS). The retrospective data can be displayed as an Ambulatory Glucose Profile $^{11}$ report, as well as in other glucometric reports, including TIR in aggregate and by time periods throughout the day to facilitate diabetes management. Two calibrations are required per day, and the device was labeled for nonadjunctive use (SMBG measurements are used to determine insulin dosing) at the time of this analysis. The device has since received nonadjunctive indication by FDA in June 2019. Worldwide, the Eversense CGM system has been available in 14 European countries and South Africa since June 2016, which was followed by the introduction of 180-day Eversense XL CGM starting in November 2017.

While pivotal accuracy and safety clinical studies are informative as to the general performance of a CGM system in a controlled environment, data derived after commercial launch of the product offer a more realistic assessment as to how the system functions in the real world. This report describes the outcome of the first 205 U.S. patients who completed the 90-day Eversense sensor wear period. Glucometrics for the 24-h time period, during the night, and over 30-day time periods; mean and median ARD compared to calibration finger stick measurements; transmitter wear time; and safety data are described.

\section{Methods}

Deidentified SG data were analyzed from the Eversense DMS. After the patient registers in DMS, their data (glucose, alerts) automatically upload when the transmitter is worn over the implanted Eversense sensor and the smartphone is able to connect to the DMS. Data from all patients in DMS from August 1, 2018 to May 11, 2019 were analyzed. As of the last date, 205 patients were identified as having reached a 90-day wear period on the Eversense system. Limited demographic data were obtained at registration, including patient sex, diabetes type, and prior CGM use.

Glucometric data were analyzed by patient using all SG values obtained over the 90-day wear period. The mean, standard deviation (SD), median, and the interquartile range (IQR) across all patients for several key metrics were computed. The patient metrics included mean SG, SD, coefficient of variation (CV), and glucose measurement index (GMI; a mathematical estimate of A1c published by Bergenstal et al. $^{12}$ ). In addition, the percent of SG values and time in minutes was computed for the following glucose ranges: $<54$, 54 to $<70,<70,70-180,>180,>180-250$, and $>250 \mathrm{mg} / \mathrm{dL}$. The metrics were calculated separately for the 24-h time period, for the nighttime period (00:00-06:00 h) only, ${ }^{11}$ and by 30 -day time periods.

The median percent transmitter wear time was calculated allowing for $20 \mathrm{~min}$ of transmitter charging time per day. Therefore, there were 284 SG points per day over 90 days as the maximum possible wear time. The wear time analysis was restricted to patients who continued to use the system after 30 days. Therefore, patients with $<30$ days of sensor use were excluded from the wear time calculation.

Sensor accuracy was assessed using paired SG and SMBG measurement values obtained during calibration. Patients supplied and used their own personal blood glucose meter. Calibration is performed about every $12 \mathrm{~h}$ (specifically twice a day, 10-14 h apart) by taking an SMBG measurement and entering it into the Eversense app. The calibration window can be extended up to $16 \mathrm{~h}$ before SG readings are blinded. The overall mean and median ARD values were calculated using all SMBG/SG paired points in aggregate and separately for the first 7 days, for 8-30, 31-60, and 61-90 days. In addition, mean and median ARD values were calculated for SG levels $<54,54-70,70-180,>180-250$, and $>250 \mathrm{mg} / \mathrm{dL}$ in the 90-day data set. For the SG level $<70 \mathrm{mg} / \mathrm{dL}$, the mean $\mathrm{AD}$ was calculated instead of the respective mean ARD. The $20 / 20 \%$ agreement rate was also reported (computed as the percentage of SG values within $20 \mathrm{mg} / \mathrm{dL}$ of the corresponding SMBG values when SMBG values are $<80 \mathrm{mg} / \mathrm{dL}$ or within $20 \%$ of the SMBG values when SMBG values are $>80 \mathrm{mg} / \mathrm{dL}$ ).

The reinsertion rate for the Eversense system was computed as the percentage of patients who obtained a second sensor or were scheduled to obtain a second sensor as of June 26, 2019.

Safety data were obtained through analysis of the Eversense complaint call logs to find all reported cases for the 205 patients during the evaluation period. Complaints related to use of the device or the procedure itself, for example, skin irritation such as redness and/or swelling, infection at the insertion site, hypoglycemia, inability to remove the sensor, and any SAEs were included in the safety analysis. 


\section{Results}

\section{Study participants}

Of the 205 patients, 110 were male, 94 were female, and 1 was unreported. With regard to diabetes type, 129 identified as type 1,18 as type 2, and 58 were unreported. Fifty patients stated that they were CGM naive, 112 had prior CGM experience, and 43 were unreported.

\section{Glucometrics, sensor wear time, accuracy, and sensor reinsertion rate}

The glucometric data summarized as the mean of the 205 patients are shown in Table 1. It is derived from 3,552,982 SG values over 14,490 patient-days of data. The mean SG was $161.8 \mathrm{mg} / \mathrm{dL}$ (median $157.2 \mathrm{mg} / \mathrm{dL}$, IQR 138.4 $178.9 \mathrm{mg} / \mathrm{dL}), \mathrm{SD}$ was $57.4 \mathrm{mg} / \mathrm{dL}$, and $\mathrm{CV}$ was 0.35 . The GMI was $7.18 \%$ (median $7.07 \%$, IQR $6.62 \%-7.59 \%$ ). The percent of SG values in hypoglycemia (SG value $<54 \mathrm{mg} / \mathrm{dL}$ ) computed over the 24 -h period was $1.2 \%$ and the equivalent time was $18.0 \mathrm{~min}$. The percent of SG values $<54 \mathrm{mg} / \mathrm{dL}$ for the nighttime period was $1.7 \%$. The percent of SG values in the range $S G$ value $<70 \mathrm{mg} / \mathrm{dL}$ computed over the $24-\mathrm{h}$ period was $4.1 \%$ and the equivalent time was $59.7 \mathrm{~min}$. The percent of SG values $<70 \mathrm{mg} / \mathrm{dL}$ during the nighttime period was $4.7 \%$. TIR was $62.3 \%$ or $897.7 \mathrm{~min}(\sim 15 \mathrm{~h})$ during the $24-\mathrm{h}$ time period and $61.8 \%$ for the nighttime. Finally, time in mild hyperglycemia was $21.9 \%$ or $315.8 \mathrm{~min}$ and significant hyperglycemia $11.6 \%$ or $166.7 \mathrm{~min}$ during the 24 -h time period and $21.5 \%$ and $12.1 \%$, respectively, for the nighttime period.

The assessment of glucometric data by 30 -day wear periods defined by $0-30,31-60$, and 61-90 days showed mean SG values of $161.9,160.4$, and $159.8 \mathrm{mg} / \mathrm{dL}$, respectively. Percent of SG values $<70 \mathrm{mg} / \mathrm{dL}$ over the same 30-day wear periods were $4.0 \%, 4.5 \%$, and $4.4 \%$, respectively. Finally, percent of SG values in the target range of $70-180 \mathrm{mg} / \mathrm{dL}$ were $62.4 \%$, $62.9 \%$, and $63.1 \%$, and percent of SG values $>180 \mathrm{mg} / \mathrm{dL}$ were $33.5 \%, 32.7 \%$, and $32.5 \%$, respectively, by the 30-day wear periods. The percent wear time of the transmitter was analyzed in a subset of the 205 patients that is expected to represent the real-world wear characteristics of the Eversense system. This group was conservatively defined as those patients who continued to use the Eversense system beyond the first 30 days after insertion (190 patients, i.e., $92 \%$ of the 205 patients). The median wear time in this group was $83.6 \%$.

The overall mean ARD calculated using all paired SMBG calibration points and the corresponding SG values was $11.2 \%$ (27,708 paired points; SD 11.3\%; median ARD 8.2\%). The mean ARD value during the first week, weeks $2-4$, and at each monthly interval was $14.8 \%$ ( $0-7$ days; 3636 paired points; SD 13.9; median ARD 11.2\%); 11.8\% (8-30 days; 7504 paired points; SD 12.0\%; median ARD 8.8\%); 10.0\% (31-60 days; 8508 paired points; SD 9.6\%; median ARD 7.4\%); and $10.4 \%$ (61-90 days; 8060 paired points; SD 10.7\%; median ARD $7.7 \%$ ), respectively. The mean $\mathrm{AD}$ for $\mathrm{SG}<54 \mathrm{mg} / \mathrm{dL}$ was $12.0 \%$ (281 paired points; SD 12.2\%; median AD 8\%). The mean $\mathrm{AD}$ for $\mathrm{SG}>54-70 \mathrm{mg} / \mathrm{dL}$ was $11.1 \%$ (934 paired point; SD $11.3 \%$; median AD 8\%). The mean ARD for SG in the range $70-180 \mathrm{mg} / \mathrm{dL}$ was $11.2 \%(17,828$ paired points; SD $10.9 \%$; median ARD $8.3 \%$ ) and for $\mathrm{SG}>180-250 \mathrm{mg} / \mathrm{dL}$ was $10.0 \%$ (5868 paired points; SD 9.5\%, median ARD 7.7\%). The $20 / 20 \%$ agreement rate was $86.3 \%$.

The sensor reinsertion rate (obtaining a second sensor after the completion of the first sensor wear) was $78.5 \%$.

\section{Safety results}

There were $10(5 \%)$ patients who reported that they experienced transient skin irritation, redness, and/or swelling after sensor insertion or removal procedures, $4(2 \%)$ patients who reported mild infection at the insertion site ( 3 treated with oral antibiotics), 3 (1.5\%) patients who reported hypoglycemia that was self-treated, $4(2 \%)$ cases of failure to remove the sensor on the first attempt, and $5(2.5 \%)$ patients who reported skin irritation to the transmitter patch/adhesive.

\section{Discussion}

The real-world data from the first 205 patients who reached 90 days of sensor wear on the Eversense CGM system in the

Table 1. Glucometric Data of the First 205 Eversense Patients for the 24-h Time Period AND During The NightTime

\begin{tabular}{|c|c|c|c|}
\hline Glucometric & $\begin{array}{l}\text { 24-H time period, } \\
\text { mean }(S D), \text { median }(I Q R)\end{array}$ & & $\begin{array}{l}\text { Nighttime 00:00-06:00, } \\
\text { mean }(S D), \text { median }(I Q R)\end{array}$ \\
\hline $\mathrm{SG}, \mathrm{mg} / \mathrm{dL}$ & 161.8 (33.3), 157.2 (138.4-178.9) & & 161.8 (36.9), 155.2 (136.6-184.0) \\
\hline $\mathrm{SD}, \mathrm{mg} / \mathrm{dL}$ & $57.4(14.8), 58.5(46.8-69.8)$ & & $56.5(16.4), 57.2(45.0-69.5)$ \\
\hline $\mathrm{CV}$ & $0.35(0.06), 0.35(0.32-0.39)$ & & $0.35(0.08), 0.35(0.31-0.40)$ \\
\hline \multirow[t]{2}{*}{ GMI\% } & 7.18 (0.80), 7.07 (6.62-7.59) & & $7.18(0.88), 7.02(6.58-7.71)$ \\
\hline & $\begin{array}{c}\% S G, \text { mean }(S D), \\
\text { median }(I Q R)\end{array}$ & $\begin{array}{l}\text { Time in minutes } \\
24-h \text { time period }\end{array}$ & $\begin{array}{l}\% S G, \text { mean }(S D) \\
\text { median }(I Q R)\end{array}$ \\
\hline$<54 \mathrm{mg} / \mathrm{dL}$ & $1.2(1.8), 0.6(0.1-1.6)$ & 18.0 & $1.7(2.9), 0.6(0.1-1.9)$ \\
\hline 54 to $<70 \mathrm{mg} / \mathrm{dL}$ & $2.9(2.5), 2.3(1.0-4.2)$ & 41.8 & $3.0(3.1), 2.3(0.8-3.9)$ \\
\hline$<70 \mathrm{mg} / \mathrm{dL}$ & $4.1(4.1), 2.9(1.2-5.7)$ & 59.7 & $4.7(5.5), 2.9(1.0-5.8)$ \\
\hline 70-180 mg/dL (TIR) & $62.3(19.0), 63.3(50.2-76.0)$ & 897.7 & $61.8(20.8), 61.9(48.4-77.1)$ \\
\hline$>180 \mathrm{mg} / \mathrm{dL}$ & 33.5 (20.3), $31.0(17.9-45.1)$ & 482.6 & $33.5(22.0), 29.8(16.3-47.5)$ \\
\hline$>180-250 \mathrm{mg} / \mathrm{dL}$ & 21.9 (9.7), $22.6(15.5-29.4)$ & 315.8 & 21.5 (10.9), $22.2(14.0-30.0)$ \\
\hline$>250 \mathrm{mg} / \mathrm{dL}$ & $11.6(12.8), 6.9(2.2-16.5)$ & 166.7 & $12.1(14.5), 6.8(1.8-16.9)$ \\
\hline
\end{tabular}

$\mathrm{CV}$, coefficient of variation; GMI, glucose measurement index; IQR, interquartile range; SD, standard deviation; SG, sensor glucose; TIR, time in range. 
United States showed promising glycemic results involving over 3.5 million SG values and $\sim 14,500$ patient-days. The mean SG was $161.8 \mathrm{mg} / \mathrm{dL}$ and the GMI, the mathematical estimate of the HbA1c, was $7.18 \%$. The CV was 0.35 , which achieved the recommended goal by Bergenstal et al. ${ }^{11}$ of $<0.36$. The time spent in the severe hypoglycemic range was $\sim 18$ min per day and TIR was $\sim 15 \mathrm{~h}$. Nighttime values were similar to the results obtained for the full 24-h time period. There was little change in glucose distribution over sequential 30-day time periods, suggesting that once the Eversense CGM system was instituted as a glucose management tool, patients had glucose values that were stable over the 90-day wear period.

In these first 205 patients wearing Eversense in the uncontrolled real-world setting since its commercial release, the target of $4 \%$ or less time in hypoglycemia $(<70 \mathrm{mg} / \mathrm{dL})$ recommended by Battelino et al. ${ }^{13}$ was nearly achieved and the TIR has exceeded some prior reports of $<60 \%$ for a CGM system not coupled to an algorithm to automate insulin delivery. ${ }^{14,15}$ In the DIAMOND study of CGM and MDI, the median TIR was $51 \%^{3}$ compared with the current report median of $63 \%$. In the DIAMOND study, predictive alarms were not possible. In a recent study by Puhr et al. with predictive alarms, the mean TIR was $61 \%-63 \%$ when the low threshold was set at $70 \mathrm{mg} / \mathrm{dL}$ and $57 \%-58.7 \%$ with the low threshold at $80 \mathrm{mg} / \mathrm{dL} .{ }^{16}$ In the STAR 3 study, which evaluated a sensor augmented pump system, ${ }^{7}$ and in the arm of the DIAMOND study that evaluated CGM with CSII, ${ }^{17}$ the TIR was $56 \%$ and $57 \%$ (median values), respectively. During the ASPIRE study of CGM and CSII with the automated feature of low glucose suspend, the time in the target range was $62 \% .{ }^{18}$ Hybrid closed loop systems have reported variable TIR, with the first commercial product, the MiniMed ${ }^{\mathrm{TM}}$ $670 \mathrm{G}$, reporting $72 \%$ due to automation of insulin delivery. ${ }^{19}$ In addition, in an article by Vigersky and McMahon evaluating 18 separate CGM TIR values across type 1 and type 2 diabetes under a number of conditions (use of adjunctive therapy, with CVD, in adolescents, with closed loop, and in hypoglycemia prone individuals) to correlate TIR with HbA1c, 13 of the 18 TIR values were $<62 \%$. ${ }^{15}$ Therefore, the TIR value achieved in this real-world setting in patients using the Eversense CGM system as a tool to manage diabetes seems comparable to many other reports of CGM use.

The overall mean ARD of $11.2 \%$ was higher than the $8.5 \%$ value reported in the pivotal trial. ${ }^{10}$ This finding was not unexpected since pivotal studies are done in a controlled clinical setting and use the YSI for the reference glucose value rather than the user's SMBGs, which are done on a variety of blood glucose meters and with techniques that at times can be suboptimal, that is, with dirty fingers. In a review of CGM systems by Heinemann et al., ${ }^{20}$ multiple comparisons of mean ARD values using either YSI or SMBG as the reference and the same sensor data demonstrated that mean ARD against SMBG values were higher than mean ARD against YSI values. As reported in Jafri et al., mean ARD values for three CGM systems, including the Eversense system compared against SMBG, were all higher than mean ARD values reported in their respective pivotal studies ${ }^{21}$ and consistent with the results obtained in this analysis. The mean ARD was highest in the first week of sensor life, likely due to biofouling from the insertion procedure, after which it improved and stayed essentially stable with values between
$10.0 \%$ and $11.8 \%$ across the rest of the 90 -day wear period. The mean ARD was also highest in the low glucose ranges, which has been described in a review of a number of CGM studies by Heinemann et al. ${ }^{20}$

The overall safety profile to date of the real-world use of the first implanted sensor was comparable to that observed in the pivotal clinical trials. ${ }^{8-10}$ There were no reported related SAEs. Reactions to the implant/removal procedures, including transient skin irritation characterized by swelling and/or redness, mild incision site infections responsive to oral antibiotics, and reports of failure to remove the sensor on first attempt were infrequent. Since the silicone-based adhesive is only required to secure the transmitter on top of the skin for a day at most, skin reactions have a low occurrence $(2.5 \%)$ compared to those reported to be as high as $40 \%-80 \%$ in pregnant women and children, respectively, by Messer et al. ${ }^{22}$ The sensor reinsertion rate was $78.5 \%$. Because this was a real-world study done on patients who obtained the Eversense system commercially, it was not possible to determine why some users did not choose to obtain another sensor. Since this is the early experience with this novel CGM system, not all users had insurance coverage, and this may well have been an issue with the reinsertion rate. In two prior pivotal studies, subject questionnaires showed that $>80 \%$ of study subjects wanted to be reinserted confirming the usability and acceptance of the Eversense device. ${ }^{10,23}$ In addition, the wear time of the transmitter indicates that patients value the real-world use of the Eversense CGM system.

The limitations of this report are that there were only 205 patients evaluated, and there were limited demographic data concerning this patient population, including not knowing the percentage of those using CSII versus MDI. Because the users obtained Eversense commercially, it was not possible to know what their prior glucose control was with regard to overall glucometrics. In addition, the adverse events (complaints) were either patient or health care provider selfreported and therefore, likely to have been underestimated. With regard to generalization of the data, it is unknown if the initial users of Eversense are representative of those who will adopt this device in the future. However, this data set represents real-world data from $\sim 14,500$ patient-days of device exposure and analyzes up to 3.5 million sensor data points.

In conclusion, the 90-day implanted Eversense CGM system appears to be a valuable and safe tool for management of diabetes with patients reinserting and using the device the majority of the time. Its use was associated with low rates of hypoglycemia and glycemic variability as measured by $\mathrm{CV}$, and a favorable time in the target range in these initial patients. The Eversense CGM should be considered as an appropriate CGM system for those patients and providers wishing to improve diabetes outcomes.

\section{Acknowledgments}

The authors thank the patients and health care providers for being the first Eversense CGM System users in the United States.

\section{Author Disclosure Statement}

P.S., S.G.-D., K.S.T., and F.R.K. are employees of Senseonics, Incorporated. 


\section{Funding Information}

Senseonics, Incorporated.

\section{References}

1. DCCT Study Group: The effect of intensive treatment of diabetes on the development and progression of long-term complications in insulin-dependent diabetes mellitus. N Engl J Med 1993;329:977-986.

2. Lind M, Polonsky W, Hirsch IB, et al.: Continuous glucose monitoring vs conventional therapy for glycemic control in adults with type 1 diabetes treated with multiple daily insulin injections: the GOLD randomized clinical trial. JAMA 2017;417:379-387.

3. Beck RW, Riddlesworth T, Ruedy K, et al.: Effect of continuous glucose monitoring on glycemic control in adults with type 1 diabetes using insulin injections: the DIAMOND randomized clinical trial. JAMA 2017;317: 371-378.

4. Olafsdottir AF, Polonsky W, Bolinder J, et al.: A randomized clinical trial of the effect of continuous glucose monitoring on nocturnal hypoglycemia, daytime hypoglycemia, glycemic variability, and hypoglycemia confidence in persons with type 1 diabetes treated with multiple daily insulin injections (GOLD-3). Diabetes Technol Ther 2017; 20:274-284.

5. Battelino T, Conget I, Olsen B, et al.: The use and efficacy of continuous glucose monitoring in type 1 diabetes treated with insulin pump therapy: a randomized controlled trial. Diabetologia 2012;55:3155-3162.

6. Pickup JC, Freeman SC, Sutton AJ: Glycaemic control in type 1 diabetes during real time continuous glucose monitoring compared with self monitoring of blood glucose: meta-analysis of randomized controlled trials using individual patient data. BMJ 2011;342:d3805.

7. Bergenstal RM, Tamborlane W, Ahmann A, et al.: Effectiveness of sensor-augmented pump therapy in type 1 diabetes. N Engl J Med 2010;363:311-320.

8. Kropff J, Choudhary P, Neupane S, et al.: Accuracy and longevity of an implantable continuous glucose sensor in the PRECISE study: a 180-day, prospective, multicenter, pivotal trail. Diabetes Care 2017;400:63-68.

9. Christiansen MP, Klaff LJ, Brazg R, et al.: A prospective multicenter evaluation of the accuracy of a novel implanted continuous glucose sensor: precise II. Diabetes Technol Ther 2018;20:197-206.

10. Christiansen MP, Klaff LJ, Bailey T, et al.: Prospective multicenter evaluation of the accuracy and safety of an implanted continuous glucose sensor: the PRECISION study. Diabetes Technol Ther 2019;21:231-237.

11. Bergenstal R, Ahmann A, Bailey T, et al.: Recommendations for standardizing glucose reporting and analysis to optimize clinical decision making in diabetes: the ambulatory glucose profile. J Diabetes Sci Technol 2013;7:562578.
12. Bergenstal RM, Beck RW, Close KL, et al.: Glucose management indicator (GMI): a new term for estimating A1C from continuous glucose monitoring. Diabetes Care 2018;41:2275-2280.

13. Battelino T, Danne T, Bergenstal RM, et al.: Clinical targets for continuous glucose monitoring data interpretation: recommendations form the international consensus on time in range. Diabetes Care 2019;42:1593-1603.

14. Danne T, Nimri R, Battelino T, et al.: International consensus on use of continuous glucose monitoring. Diabetes Care 2017;40:1631-1640.

15. Vigersky RA, McMahon C: The relationship of hemoglobin A1c to time-in-range in patients with diabetes. Diabetes Technol Ther 2019;21:81-85.

16. Puhr S, Derdzinski M, Welsh JB, et al.: Real-world hypoglycemia avoidance with a continuous glucose monitoring system's predictive low glucose alert. Diabetes Technol Ther 2019;21:155-158.

17. Beck RW, Riddlesworth TD, Ruedy KJ, et al.: Effect of initiating use of an insulin pump in adults with type 1 diabetes using multiple daily insulin injections and continuous glucose monitoring (DIAMOND): a multicenter, randomized controlled trial. Lancet Diabetes Endocrinol 2017;5:700708.

18. Bergenstal RM, Klonoff DC, Garg SK, et al.: Thresholdbased insulin interruption for reduction of hypoglycemia. N Engl J Med 2013;369:224-232.

19. Bergenstal RM, Garg S, Weinzimer SA: Safety of a hybrid closed-loop insulin delivery system in patients with type 1 diabetes. JAMA 2016;316:1407-1408.

20. Heinemann L, Schoemaker M, Schmelseisen-Redecker G, et al:: Benefits and limitations of MARD as a performance parameter for continuous glucose monitoring in the interstitial space. J Diabetes Sci Technol 2019. [Epub ahead of print]; DOI: 10.1177/1932296819855670.

21. Jafri RZ, Balliro CA, El-Khatib F, et al.: A three-way accuracy comparison of the Dexcom G5, Abbott Freestyle Libre Pro and Senseonics Eversense Devices in an outpatient study of subjects with type 1 diabetes. Diabetes 2018; 67(Suppl 1):14-OR.

22. Messer LH, Berget C, Beatson C, et al.: Preserving skin integrity with chronic device use in diabetes. Diabetes Technol Ther 2018;20:S254-S264.

23. Barnard KD, Kropff J, Choudhary P, et al.: Accceptability of implantable continuous glucose monitoring sensor. J Diabetes Sci Technol 2018;12:634-638.

Address correspondence to: Katherine S. Tweden, PhD Senseonics, Incorporated 20451 Seneca Meadows Parkway Germantown, MD 20876

E-mail: katherine.tweden@senseonics.com 